\title{
STUDY OF PULMONARY FUNCTION IMPAIRMENT IN TREATED PULMONARY AND PLEURAL TUBERCULOSIS
}

\author{
A.Vinay Kumar ${ }^{1}$, K. Raj Kumar ${ }^{2}$, M.Raghu Vamsi ${ }^{3}$. \\ ${ }^{1}$ Professor \& HOD, Department of Pulmonary medicine Chalmeda Anand Rao Institute of Medi- \\ cal Sciences, Karimnagar, Talangana, India. \\ ${ }^{2}$ Associate Professor Department of Pulmonary medicine Chalmeda Anand Rao Institute of Medi- \\ cal Sciences, Karimnagar, Talangana, India. \\ *3 Junior Resident Department of Pulmonary medicine Chalmeda Anand Rao Institute of Medical \\ Sciences, Karimnagar, Talangana, India.
}

\section{ABSTRACT}

Aim/Objectives: To study pulmonary function of patients in treated pulmonary and pleural tuberculosis.

Materials and Methods: This study was a Cross sectional analysis of 131 patients attending out patients department of pulmonary medicine in Chalmeda Anand Rao Institute of Medical Sciences, Karimnagar, Telangana, India.

Results: Among 131 cases, 39 (29.77\%) showed Obstructive pattern, 40 cases $(30.53 \%)$ cases showed Restrictive pattern and 27 cases (20.61\%)showed mixed pattern abnormality. Obstructive pattern is predominant in pulmonary cases and restrictive in pleural cases.

Conclusion: FEV1 was found to be grossly reduced in the study group especially pulmonary tuberculosis in comparison to control. Forced vital capacity was also significantly reduced in study group and more predominant in treated pleural tuberculosis cases, where FEV1 was not significantly reduced.This study revealed that more advanced lesions of tuberculosis will lead to long term morbidity of the patients because of pulmonary derangements.

KEY WORDS: Pulmonary Function Test, Body Mass Index,Tuberculosis, Spirometry.

Address for correspondence: Dr. M.Raghu Vamsi, Junior resident Department of Pulmonary medicine Chalmeda Anand Rao Institute of Medical Sciences, Karimnagar, Talangana, India.

E-Mail: dr.raghuvamshi@gmail.com

\begin{tabular}{|c|c|c|}
\hline \multicolumn{3}{|c|}{ Online Access and Article Informtaion } \\
\hline \multirow{2}{*}{$\begin{array}{l}\text { Quick Response code } \\
\text { DOI: } 10.16965 / \text { ijims.2018.111 }\end{array}$} & \multicolumn{2}{|c|}{$\begin{array}{l}\text { International Journal of Integrative Medical Sciences } \\
\text { www.imedsciences.com }\end{array}$} \\
\hline & $\begin{array}{l}\text { Received: } 28-04-2018 \\
\text { Reviewed: } 28-04-2018\end{array}$ & $\begin{array}{l}\text { Accepted: 25-05-2018 } \\
\text { Published: 05-06-2018 }\end{array}$ \\
\hline Source of Funding: Self & \multicolumn{2}{|c|}{ Conflicts of interest: None } \\
\hline
\end{tabular}

\section{BACKGROUND}

Tuberculosis is a disease of concern for the mankind since the time immemorial. It is now ranked as the second human killer amongst all infectious diseases globally $\left({ }^{12}\right)$.It was estimated that out of 2.2 million annual incidence of tuberculosis cases in India 0.87 million were infective cases. India shoulders the $1 / 5$ th of the globally TB burden, about $40 \%$ of Indian population is infected with TB bacillus. Prevalence is

\section{5 million $[1,2]$.}

Pulmonary tuberculosis affects the lung parenchyma and thereby causes many structural and functional changes in the lungs. These changes lead to functional disability of the patients leading to significant morbidity. The functional changes may lead to severe disability in the patients even after successful anti tubercular treatment. Pulmonary tuberculosis involves lung parenchyma, pleura and at times bronchi. The 
pathological features consist of exudation, caseation, cavitation \& fibrosis in variable degrees, the lesions are general described as pleomorphic. These lesions impair lung function depending on the extent of involvement of lung parenchyma [3-5].

The functional abnormalities comprise of restriction of lung volumes decrease in lung compliance \& impaired gas transfer. It may also lead to generalized airflow obstruction when there is extensive involvement of airways. Involvement of pleura along with adhesion to the diaphragm may lead to restrictive lung disease and hypoxemia [6-11].

\section{MATERIALS AND METHODS}

A Hospital based cross sectional study was carried out at Chalmeda Anand Rao Institute Of Medical Sciences, Karimnagar. Over a periods of 2yrs from October 152015 to October 2017. In study period of 24 months among patients attending pulmonary medicine outpatient department 131 patients were selected.

Detailed history, clinical examination, Basic investigations and Pulmonary function test was done. Spirometry technique explained to the patient and three attempts were recorded and the best of three considered if the variation between two readings is less. FEV1, FVC, FEV1/ FVC recorded. Salbutamol inhaler given and waited for $30 \mathrm{~min}$. Post bronchodilator test recorded.

Permission to conduct the study was obtained from institutional ethics committee(IEC). Chalmeda Anand Rao Institute Of Medical Sciences, Bommakal, Karimnagar. Informed oral consent was obtained from all patients.

\section{Inclusion Criteria:}

1. Adult $>18$ yearsage.

2. Pulmonary tuberculosis patients who has taken full course of ATT.

3. Presenting with Dyspnea, cough.

4. Sputum AFB - Negative .

5. $X$ ray chest - normal, or showing inactive lesions, sequalae of TB like fibrosis, cavity, calcifications, bronchiectactic changes.

6. Non smoker.

\section{Exclusion Criteria:}

1. Smoker - present and past.
2. Bronchial Asthma.

3. $X$ ray chest - suggestive of active lesions.

4. Sputum AFB -Positive.

5. History and clinical features suggestive of active pulmonary tuberculosis.

6. Interstitial lung diseases.

7. Cardiac diseases.

8. Anemia.

9. History of occupational lung diseases.

\section{RESULTS}

Total 131 cases were taken into study

\begin{tabular}{|c|c|c|c|}
\cline { 2 - 4 } Table 1: Gender. & Gender & Study $\mathbf{n = 1 3 1}$ & $\mathbf{\%}$ \\
\cline { 2 - 4 } & Males & 89 & 67.9 \\
\cline { 2 - 4 } & Females & 42 & 32.06 \\
\hline
\end{tabular}

Among total cases of 131 patients 89 (67.9\%) were males and 42(32.06\%) were females.

Table 2: Age Distribution.

\begin{tabular}{|c|c|c|}
\hline Age & Study $\mathbf{n = 1 3 1}$ & $\%$ \\
\hline $\mathbf{1 8 - 2 5}$ & 26 & 19.84 \\
\hline $\mathbf{2 6 - 3 5}$ & 29 & 22.13 \\
\hline $\mathbf{3 6 - 4 5}$ & 23 & 17.55 \\
\hline $\mathbf{4 6 - 5 5}$ & 19 & 14.5 \\
\hline $\mathbf{5 6 - 6 5}$ & 28 & 21.37 \\
\hline $\mathbf{6 6 - 7 5}$ & 6 & 4.58 \\
\hline
\end{tabular}

Among 131 cases $22.1 \%$ were between 2635years,

Graph 1: Showing the BMI recording

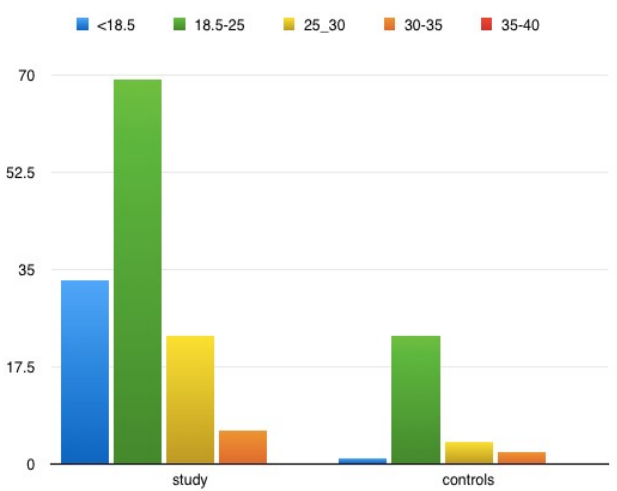

The mean BMI of the study group was $20.8+/-4.2$

The mean BMI of control were $23+/-3.2$

Table 3: OBST / REST / MIXED.

The spirometry reports of study participants were assessed according to the severity of their radiological lesions

\begin{tabular}{|c|c|c|}
\hline Type & Number & $\%$ \\
\hline Obstructive & 39 & 29.77 \\
\hline Restrictive & 24 & 18.32 \\
\hline Mixed & 18 & 13.74 \\
\hline Normal & 20 & 15.26 \\
\hline
\end{tabular}


Table 4: Pleural Effusion Cases.

\begin{tabular}{|c|c|c|}
\hline Type & Number & $\%$ \\
\hline Obstructive & 0 & 0 \\
\hline Restrictive & 16 & 12.21 \\
\hline Mixed & 9 & 6.87 \\
\hline Normal & 5 & 3.81 \\
\hline
\end{tabular}

Among 131 cases 39 (29.77\%)showed Obstructive pattern, 40 cases (30.53\%)cases showed Restrictive pattern and 27cases (20.61\%)cases showed mixed pattern abnormality. Obstructive pattern is predominant in pulmonary cases and restrictive in pleural cases.

\section{DISCUSSION}

Tuberculosis affecting lungs usually disturbs pulmonary functions. The impairment of pulmonary function is more with far advanced variety of tuberculosis as evident by various workers. And this far advanced tuberculosis is due to delayed approach for treatment and incomplete antitubercular treatment. Total of 131 cases have been evaluated in the present study, the pulmonary functions were examined and tabulated for analysis. The mean age of the study group $41.44+/-16.89$, most of the patients (57.3\%) belong to age group 18years-45 years. In our study restrictive defect is seen in $30.53 \%$ cases. Restrictive lung disease as most common followed by obstructive defect.

Pulmonary function impairment as a complications of TB manifest as various pattern but mainly as airflow limitation. In Platino et al. study spirometric indices compared many subjects with and without diagnosis of Tuberculosis. With Tuberculosis performed less well although relative difference tend to be greater for FEV1 than FVC . History of TB was clearly associated with more severe grades of obstruction [6].

Another study found that after 15 years follow up of patients there was a higher decline in FVC than FEV1. Extensive disease may produce restrictive changes due to lung parenchymal destruction.

The loss of lung function was highest within 6 months of diagnosis of pulmonary tuberculosis and stabilized after 12 months when loss is considered as chronic [7].

Anti tuberculosis treatment improves lung function in pulmonary tuberculosis patients but a proportion of patients left with residual pulmonary impairment [8-10] due to parenchymal fibrosis, cavitation, bronchiectasis, pleural thickening etc. Extensive TB lesions may produce restrictive changes with reduced transfer of carbon monoxide in the lung [11].

Post tubercular pulmonary impairment emerges as distinct entity in various pattern but mainly as airflow limitation, and previous tuberculosis is considered as risk factor for COPD [12].

\section{CONCLUSION}

This study revealed that more advanced lesions of tuberculosis will lead to long term morbidity of the patients because of pulmonary derangements. Delayed approach for treatment with incomplete treatment with anti tubercular drugs lead to severe pulmonary derangements. So the early detection and treatment of tuberculosis are important measures to be taken to reduce the chances of development of chronic airflow limitations. So emphasis should be given for the proper management and follow up of cases according to RNTCP guidelines to prevent morbidity.

\section{REFERENCES}

[1] Tbcindia.nic.in/pdfs/RNTCP\%20at\%20a\%20 glance. pdf RNTCP at a Glance

[2]. WHO Library cataloguing-in-publication data: chapter 2 ; The burden of disease caused by TB. Global Tuberculosis Report - 2013.

[3]. GlobalHallettwy, Maslin cJ. The different obstructive Pulmonary syndrome in a tuberculosis sanitorium etiological factors. Ann intern Med 1961;54:1146-1155.

[4]. Wright Gw. Tuberculosis and Pneumonia. In Fern wo, Rahn $\mathrm{H}$ eds Handbook of physiology, Washington DC, American Physilogical society; 1965;16151622.

[5]. S.K.Verma, S. Kumar, Kiran Vishnu Narayan, R. Sodhi. Post Tubercular Obstuctive Airway Impairment Review article. Indian J Allergy Asthma Immunol 2009;23(2):95-99.

[6]. A.M.B.Menezes, P. C. Hallal, R. Perez-Padilla, J. R. B. , Jardim A. Muino, M. V. Lopez et al. The Latin American Project for the investigation of obstructive lung disease (PLATINO) Team. Tuberculosis and airflow obstruction evidence from PLATINO study in Latin America EurRespir.J 2007;30:1-6.

[7]. Lee $\mathrm{JH}$, chang $\mathrm{JH}$, Lung function in patients with chronic airflow obstruction due to tuberculosis destroyed lung Respir. Med 2003;97;1237-42. 
[8]. Mikhail Chushkin, MD; SergryYartsev, MD; DmitriyZhutikov, MD; Elena Bogorodskaya, MD; Sergey Smerdin, MD The impairment of Respiratory Function in Patients with Treated Pulmonary Tuberculosis Chest 2011;140 (4_MeetingAbstracts): 786A. doi: 10. 1378/chest. 1083625 .

[9]. Nefedov VB, Smirnova DG, Disorders of pulmonary functionin patients with destructive tuberculosis .Probl Tuberk 1991;11:51-4.

[10]. Verma SK, Narayan KV, Kumar S. Astudy on prevalenc of obstructive airway disease among post pulmonary tuberculosis patients. Pulmon 2009;11(1):47.
[11]. Hallet WY, Martin CJ.The diffuse obstructive pulmonary syndromein a tuberculosis santorium. I.Etiologic factors .Ann Intern Med1961;54:114655.

[12]. Hnizdo E, Singh T, Churchyard GJ, chronic pulmonary function impairment caused by initial and recurrent Pulmonary tuberculosis following treatment. Thorax 2000;55:32-38.

How to cite this article: A.Vinay Kumar, K. Raj Kumar, M. Raghu Vamsi. STUDY OF PULMONARY FUNCTION IMPAIRMENT IN TREATED PULMONARY AND PLEURAL TUBERCULOSIS. Int J Intg Med Sci 2018;5(5):626-629. DOI: 10.16965/ijims.2018.111

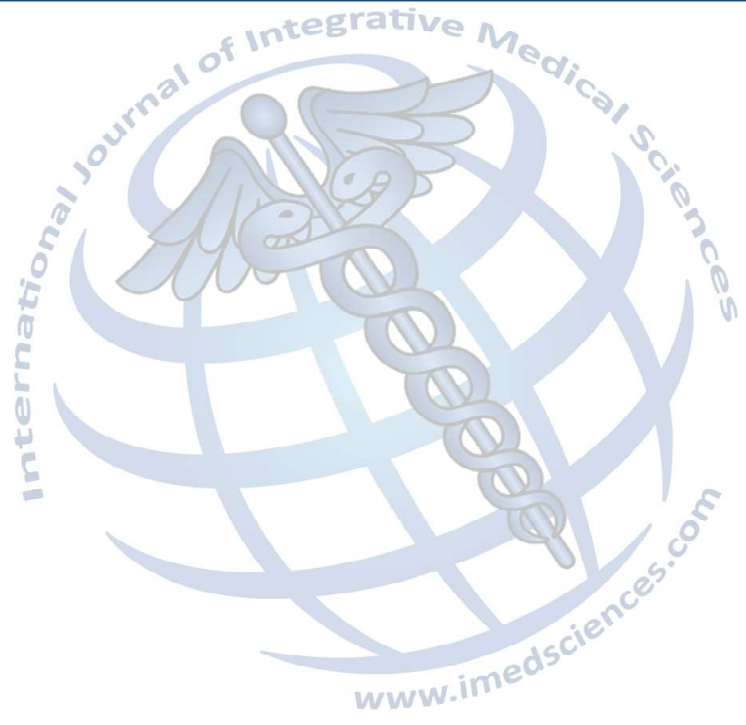

